\title{
Influence of Whey Protein Micro-Gel Particles and Whey Protein Micro-Gel Particles-Xanthan Gum Complexes on the Stability of O/W Emulsions
}

\author{
Man Zhang ${ }^{1,+}$, Bin Liang ${ }^{2,+}$, Hongjun $\mathrm{He}^{1}{ }^{1}$, Changjian $\mathrm{Ji}^{3}$, Tingting Cui ${ }^{4}\left(\mathbb{D}\right.$ and Chanchan Sun ${ }^{1, *}$ (1) \\ 1 College of Life Sciences, Yantai University, Yantai 264005, China; 20172905850@m.ldu.edu.cn (M.Z.); \\ hemiles@ytu.edu.cn (H.H.) \\ 2 College of Food Engineering, Ludong University, Yantai 264025, China; liangbin1989311@163.com \\ 3 Department of Physics and Electronic Engineering, Qilu Normal University, Jinan 250200, China; \\ sdejcj@qlnu.edu.cn \\ 4 Key Laboratory of Food Nutrition and Safety, Tianjin University of Science \& Technology, \\ Ministry of Education, Tianjin 300457, China; tingtingcui@sdas.org \\ * Correspondence: sunchan88@126.com \\ + These authors contributed to the work equally and should be regarded as co-first authors.
}

Citation: Zhang, M.; Liang, B.; He, H.; Ji, C.; Cui, T.; Sun, C. Influence of Whey Protein Micro-Gel Particles and Whey Protein Micro-Gel Particles-Xanthan GUM Complexes on the Stability of O/W Emulsions. Polymers 2021, 13, 2301. https:// doi.org/10.3390/polym13142301

Academic Editor: Eduardo Guzmán

Received: 17 June 2021

Accepted: 9 July 2021

Published: 14 July 2021

Publisher's Note: MDPI stays neutral with regard to jurisdictional claims in published maps and institutional affiliations.

Copyright: (c) 2021 by the authors. Licensee MDPI, Basel, Switzerland. This article is an open access article distributed under the terms and conditions of the Creative Commons Attribution (CC BY) license (https:// creativecommons.org/licenses/by/ $4.0 /)$.

\begin{abstract}
Appropriate pretreatment of proteins and addition of xanthan gum (XG) has the potential to improve the stability of oil-in-water $(\mathrm{O} / \mathrm{W})$ emulsions. However, the factors that regulate the enhancement and the mechanism are still not clear, which restricts the realization of improving the emulsion stability by directional design of its structure. Therefore, the effects of whey protein micro-gel particles (WPMPs) and WPMPs-XG complexes on the stability of $\mathrm{O} / \mathrm{W}$ emulsion were investigated in this article to provide theoretical support. WPMPs with different structures were prepared by pretreatment (controlled high-speed shear treatment of heat-set WPC gels) at pH 3.5-8.5. The impact of initial WPC structure and XG addition on Turbiscan Indexes, mean droplet size and the peroxide values of $\mathrm{O} / \mathrm{W}$ emulsions was investigated. The results indicate that WPMPs and XG can respectively inhibit droplet coalescence and gravitational separation to improve the physical stability of WPC-stabilized O/W emulsions. The pretreatment significantly enhanced the oxidative stability of WPC-stabilized O/W emulsions. The addition of XG did not necessarily enhance the oxidative stability of $\mathrm{O} / \mathrm{W}$ emulsions. Whether the oxidative stability of the $\mathrm{O} / \mathrm{W}$ emulsion with $\mathrm{XG}$ is increased or decreased depends on the interface structure of the protein-XG complex. This study has significant implications for the development of novel structures containing lipid phases that are susceptible to oxidation.
\end{abstract}

Keywords: whey protein concentration micro-gel particles; xanthan gum; stability; O/W emulsion

\section{Introduction}

Oil-in-water $(\mathrm{O} / \mathrm{W})$ emulsions such as salad dressing, soups, sausages, and mayonnaise represent important systems in the food industry. Their high stability, including storage stability and oxidative stability, is the basis of other functional properties. Therefore, a variety of emulsifiers including macromolecular proteins, polysaccharides and low molecule weight surfactants are introduced to stabilize the emulsions and inhibit lipid oxidation.

Whey protein (WP) has been widely used as emulsifier in various emulsion products such as mayonnaise and ice cream, which attributed to its high nutritional quality and excellent functional properties [1]. Many studies have confirmed that an interfacial WP layer may inhibit lipid oxidation due to its ability to form a physical barrier between the continuous phase and dispersed phase, chelate pro-oxidant transition metals and scavenge free radicals [2]. However, WP-based emulsions are very sensitive to destabilization, 
especially when the temperature and $\mathrm{pH}$ are changed. Moreover, lipid and protein cooxidation lead to instability of the emulsions, decreased sensory properties and nutritional values [3]. Thus, steps must be taken to improve the stability of the WP-stabilized emulsions. The functional properties of proteins can be enhanced using many techniques such as heating, ultrasound, high-pressure treatment, and cross-linking with the usage of different enzymes [4]. It can be seen that proper pretreatment can enhance the stability of proteinstabilized emulsions. Our previous studies found that the controlled high-speed shear treatment of heat-set WP gel could significantly enhance the emulsifying properties and emulsifying stability of WP [5]. However, the influence of the controlled high-speed shear treatment of heat-set WP gel on the stability of WP-stabilized emulsion is still unclear.

Xanthan gum (XG) is one of the most important functional biopolymers added to $\mathrm{O} / \mathrm{W}$ emulsions, and used as stabilizer due to its thickening and gelling properties [6]. However, due to its poor interfacial activity, XG is rarely used alone, but rather in combination with other emulsifiers in emulsions. Recent studies have shown that both the physical stability and oxidative stability of $\mathrm{O} / \mathrm{W}$ emulsions stabilized by proteins can be enhanced by adding XG $[7,8]$. They concluded that this could be attributed to the increased thickness of the interfacial layer, the changing rheological properties of the emulsions and the ability to chelate metal ions of XG. However, the results of Griffin and Khouryieh [9] showed that at every $\mathrm{NaCl}$ concentration, the secondary lipid oxidation products (TBARS) concentration of WP-XG emulsion at $\mathrm{pH} 7$ was significantly higher than that of other groups. Thus, the effect of XG on stability of protein-stabilized emulsions is not always enhancement, depending on some factors. However, the effect factors and mechanism are not clear, which restricts the realization of enhanced stability by the fine design of $\mathrm{O} / \mathrm{W}$ emulsion structure.

The interactions between polysaccharides and proteins depend on the distribution of functional groups (e.g., charged and hydrophobic, etc.) and environmental conditions (e.g., $\mathrm{pH}$ and biopolymer ratios, etc.) [10]. Under the influence of the environmental conditions and the distribution of various functional groups, protein/polysaccharide mixtures in an aqueous dispersion are often accompanied by either segregative/associative phase separation through thermodynamic incompatibility or compatibility [11]. Therefore, the functional properties and structure of protein-polysaccharide complex emulsifiers can be regulated by the modification of protein structure.

In this article, WPC micro-gel particles (WPMPs) with different molecular structures were prepared by the controlled high-speed shear treatment of heat-set WPC gels at $\mathrm{pH}$ 3.5-8.5. The impact of XG addition on the short-term stability, mean lipid droplet size and the peroxide values (PVs) of WPC and WPMPs-stabilized O/W emulsions was investigated to determine whether WPMPs and WPMP-XG complexes-stabilized emulsions would provide better physical and oxidative stability than WPC and WPC-XG complexes-stabilized emulsions. The differences of the emulsifiers (proteins and protein-XG complexes) structure were characterized by a Rheolaser Lab micro-rheometer based on multi-speckle diffusing wave spectroscopy (DWS). The influence of whey protein micro-gel particles and whey protein micro-gel particles-xanthan gum complexes on the stability of $\mathrm{O} / \mathrm{W}$ emulsion was evaluated by using Turbiscan Lab ${ }^{\circledR}$ Expert stability analysis. By exploring the correlation between the differences of the initial structure of proteins and protein-XG complexes and emulsion stability, the article will provide theoretical support for the directional design of food emulsion structure to improve its stability.

\section{Materials and Methods}

\subsection{Materials}

Whey protein concentrate (WPC) powder was supplied by Fonterra Commercial Trading Co., Ltd. (Shanghai, China). The composition of WPC as specified by the manufacturer was $80.3 \%$ protein (wet basis), $6.9 \%$ carbohydrate, $5.1 \%$ moisture, $3.8 \%$ fat, and $3.9 \%$ ash. XG (Ziboxan ${ }^{\circledR} \mathrm{TW}$ ) was of analytical grade and obtained from Deosen Co., Ltd. (Shanghai, China). Soybean oil was obtained from COFCO Co. Ltd. (Beijing, China). Methanol, 
chloroform, $\mathrm{NaOH}, \mathrm{HCl}$, ferrous chloride, and potassium thiocyanate (analytical grade) were purchased from Sinopharm Co. Ltd. (Beijing, China).

\subsection{Whey Protein Micro-Gel Particles Preparation}

WPC powder $(12 \mathrm{~g})$ was dispersed in $100 \mathrm{~mL}$ distilled water by stirring for $2 \mathrm{~h}$ at $25^{\circ} \mathrm{C}$ to ensure complete hydration of the proteins. And then, the $\mathrm{pH}$ of the WPC dispersions were separately adjusted to $\mathrm{pH} 3.5, \mathrm{pH} 4.5, \mathrm{pH} 5.5, \mathrm{pH} 6.5, \mathrm{pH} 7.5$, and $\mathrm{pH} 8.5$ using $0.1 \mathrm{~mol} / \mathrm{L} \mathrm{HCl}$ or $0.1 \mathrm{~mol} / \mathrm{L} \mathrm{NaOH}$ solution. The dispersions were thermally-crosslinked by heating at $85^{\circ} \mathrm{C}$ for $16 \mathrm{~min}$ in a water bath. And then, the samples were cooled with cold water $\left(0^{\circ} \mathrm{C}\right)$ for $10 \mathrm{~min}$ and held at $4{ }^{\circ} \mathrm{C}$ for $10 \mathrm{~h}$. After homogenizing with an Ultra-Turrax T25 high-speed homogenizer (IKA, Staufen, Germany) at 10,000 r/min for $4 \mathrm{~min}$, the $\mathrm{pH}$ of the dispersions was all adjusted to $\mathrm{pH} 6.5$ using the above $\mathrm{NaOH}$ and $\mathrm{HCl}$ solution. In order to eliminate the influence of $\mathrm{Na}^{+}$concentration on the results, $1 \mathrm{~mol} / \mathrm{L} \mathrm{NaCl}$ solution was used to make the concentration of $\mathrm{Na}^{+}$equal in each test sample. Suspensions of WPC micro-gel particles (WPMP) were obtained and named WPMP(3.5), WPMP(4.5), WPMP(5.5), WPMP(6.5), WPMP(7.5) and WPMP(8.5).

\subsection{Particle Size Distribution Measurements of WPMPs}

Immediately after preparation, particle size distributions of WPC and WPMP suspensions were respectively measured using dynamic light scattering-based particle size analyzers (BT-9300S and BT-2001, Dandong Bettersize Instruments Ltd., Dandong, China) at $25^{\circ} \mathrm{C}$. The laser analyzer is based on dynamic light scattering (DLS). The Stokes-Einstein equation was used to calculate the particle size and distribution.

\subsection{WPMP-XG Complexes Preparation}

Powdered XG (1 g) was dispersed in $30 \mathrm{~mL}$ MilliQ water and then stirred at $80{ }^{\circ} \mathrm{C}$ for $30 \mathrm{~min}$. Subsequently, the WPMP dispersions and XG solution $(7: 3, w / w)$ were mixed by stirring (AHM-P125A hand-held mixer, Appliance Company of America (Zhuhai) CO., LTD, Zhuhai, China) at $200 \mathrm{r} / \mathrm{min}$ for $5 \mathrm{~min}$. The complexes of XG and WPMP(3.5), WPMP(4.5), WPMP(5.5), WPMP(6.5), WPMP(7.5), WPMP(8.5) were named WPMP(3.5)XG, WPMP(4.5)-XG, WPMP(5.5)-XG, WPMP(6.5)-XG, WPMP(7.5)-XG and WPMP(8.5)-XG, respectively. The ultimate ratio of protein: $\mathrm{XG}$ is 7.5:1 $(w / w)$ in the protein-XG complexes.

\subsection{Micro-Rheology Measurements of WPMP Dispersions and WPMP-XG Complexes}

A commercial Rheolaser Master analyser (Formulaction Inc., l'Union, France), used to measure the micro-rheological properties of WPMP dispersions and WPMP-XG complexes, is based on diffuse wave spectroscopy (DWS). Immediately after preparation, $20 \mathrm{~mL}$ of liquid samples were placed into flat-bottomed cylindrical glass tubes (height of $140 \mathrm{~mm}$, diameter of $16 \mathrm{~mm}$ ). The temperature of all the samples was set to $25^{\circ} \mathrm{C}$. And then, the first measurement of the backscattered light was made. Micro-rheological properties, including the elasticity index (EI), macroscopic viscosity index (MVI), solid-liquid balance (SLB) and fluidity index (FI), were obtained from the mean square displacement curves [12].

\subsection{Emulsion Preparation}

Emulsions containing 20\% $(w / w)$ soybean oil were prepared with soybean oil and WPMP dispersions and WPMP-XG complexes using a high-shear homogenizer IKA UltraTurrax T25 (IKA) at 10,000 r/min for $5 \mathrm{~min}$ at $25^{\circ} \mathrm{C}$.

\subsection{Short-Term Stability Measurement of Emulsions}

Immediately after preparation, $20 \mathrm{~mL}$ of liquid samples were placed into flat-bottomed cylindrical glass tubes (height of $140 \mathrm{~mm}$, diameter of $16 \mathrm{~mm}$ ). And then, the stability of all the emulsions was evaluated using Turbiscan Lab ${ }^{\circledR}$ Expert stability analysis (Formulaction) and multiple light scattering principle [13]. The Turbiscan Stability Indexes (TSI) as a 
function of short-term $(24 \mathrm{~h})$ were calculated according to backscattered light intensity values [14]:

$$
\mathrm{TSI}=\sqrt{\frac{\sum_{i-1}^{n}\left(x_{i}-x_{B S}\right)}{n-1}}
$$

where, $x_{i}$ is the backscattered light intensity values of every scan; $x_{B S}$ is the mean of backscattered light intensity values; $\mathrm{n}$ is the number of scans.

\subsection{Mean Droplet Size of Emulsions}

For backscattered light intensity, it is also affected by droplet size and volume concentration of oil. Thus, the droplet size as a function of short-term $(24 \mathrm{~h})$ can be calculated according to the following formula:

$$
\mathrm{BS}=\sqrt{\frac{3 \varnothing(1-g) Q_{s}}{2 d}}
$$

where, BS is the backscattered light intensity values; $\varnothing$ is the volume concentration of oil; $g$ and $Q_{S}$ are the optical parameters based on Mie theory; $\mathrm{d}$ is the mean droplet size, $\mathrm{nm}$.

\subsection{Determination of the Peroxide Values (PVs) of the Emulsions}

The emulsions stabilized by WPMP and WPMP-XG complexes were stored at $30^{\circ} \mathrm{C}$ for $17 \mathrm{~d}$. Every $24 \mathrm{~h}, 2 \mathrm{~g}$ samples of each emulsion were placed in a flask and dissolved with $6 \mathrm{~mL}$ of a mixture of trichloromethane/methanol $(7: 3, \mathrm{v}: \mathrm{v})$ [15]. After vortexing three times, the mixture was centrifuged at $10,000 \times g$ for $5 \mathrm{~min} .0 .2 \mathrm{~mL}$ of the extract (lower layer) was removed to measure the PVs.

The PVs was determined according to the method outlined in GB/T 5009.37-2003 [16] with a slight modification. The extract was diluted with $4.8 \mathrm{~mL}$ or $9.8 \mathrm{~mL}$ of trichloromethane/ methanol $(7: 3, \mathrm{v}: \mathrm{v})$. The mixtures were then reacted with $15 \mu \mathrm{L}$ of ferrous chloride mixed solution $(0.03 \mathrm{~mol} / \mathrm{L}$ ferrous chloride and $0.5 \mathrm{~mol} / \mathrm{L} \mathrm{HCl})$ and $15 \mu \mathrm{L}$ of $0.3 \mathrm{~mol} / \mathrm{L}$ potassium thiocyanate solution. After full mixing with vortex, the samples were incubated for $5 \mathrm{~min}$ at $25^{\circ} \mathrm{C}$ in the dark. The absorbances were measured at $500 \mathrm{~nm}$ using a TU-1810 ultraviolet spectrophotometer (Persee General Instrument Co., Ltd., Beijing, China). The PVs (expressed as milligram equivalent of hydroperoxide per kilogram of oil) was quantified according to Equation (2):

$$
\mathrm{PV}(\mathrm{meq} / \mathrm{kg})=\frac{C-C_{0}}{0.6 \times m \times D \times 55.94 \times 2}
$$

where $C$ and $C_{0}$ are the iron contents ( $\mu \mathrm{g}$ ) of the emulsions and blank, respectively, which were calculated based on the standard curve; $m$ is the weight of the emulsions, $g$; and $D$ is a dilution factor, 75 or 150 .

\subsection{Statistical Analysis}

All measurements were performed a minimum of three times and the resulting datas were expressed as mean \pm standard deviation (SD). Statistical analyses were performed by the Tukey post hoc test with one-way ANOVA, with $p<0.05$ considered significant.

\section{Results and Discussion}

\subsection{Particle Size Distribution of WPMPs}

As shown in Figure 1, all the particle sizes of WPC and WPMPs presented a normal distribution (unimodal distribution). Al the samples also had a narrow size distribution. Thus, the protein size can be characterized by mean particle size $\left(D_{50}\right)$ as shown in Table 1. WPC is a group of globular proteins with $D_{50}$ of about $45.86 \mu \mathrm{m}$. $D_{50}$ of WPMPs which were formed by controlled thermal denaturation of WPC at $\mathrm{pH} 3.5, \mathrm{pH} 4.5, \mathrm{pH} 5.5, \mathrm{pH}$ 6.5, $\mathrm{pH} 7.5$ and pH 8.5 were $7.54 \mu \mathrm{m}, 4.91 \mu \mathrm{m}, 13.96 \mu \mathrm{m}, 6.19 \mu \mathrm{m}, 17.74 \mu \mathrm{m}$, and $46.68 \mu \mathrm{m}$. In the $\mathrm{pH}$ range of 3.5-5.5, with the increase of $\mathrm{pH}$, particle sizes of WPMPs decreased first 
and then increased gradually. As the $\mathrm{pH}$ continued to rise from 5.5 to 8.5 , the $D_{50}$ of WPMPs gradually increased as the $\mathrm{pH}$ increased. The results are consistent with the research of Chen et al. [17]. They believed that the difference in particle size of protein gel particles is due to the redistribution of inner structure of protein molecules during heat treatment at different $\mathrm{pH}$ and cooling process. According to Liu et al. [18], the network structure and texture in a heat-induced whey protein gel largely depends on the balance between attractive and repulsive forces among denatured protein molecules during aggregation which effected by the $\mathrm{pH}$ values of the dispersions. Thus, the larger particle size of WPMP(5.5) than WPMP(4.5) and WPMP(6.5) may be due to the higher hardness of heat-set WPC gel formed at $\mathrm{pH} 5.5$ than those formed at $\mathrm{pH} 4.5$ and $\mathrm{pH} 6.5$ [19], which is harder to be destroyed during the controlled high-speed shear treatment.

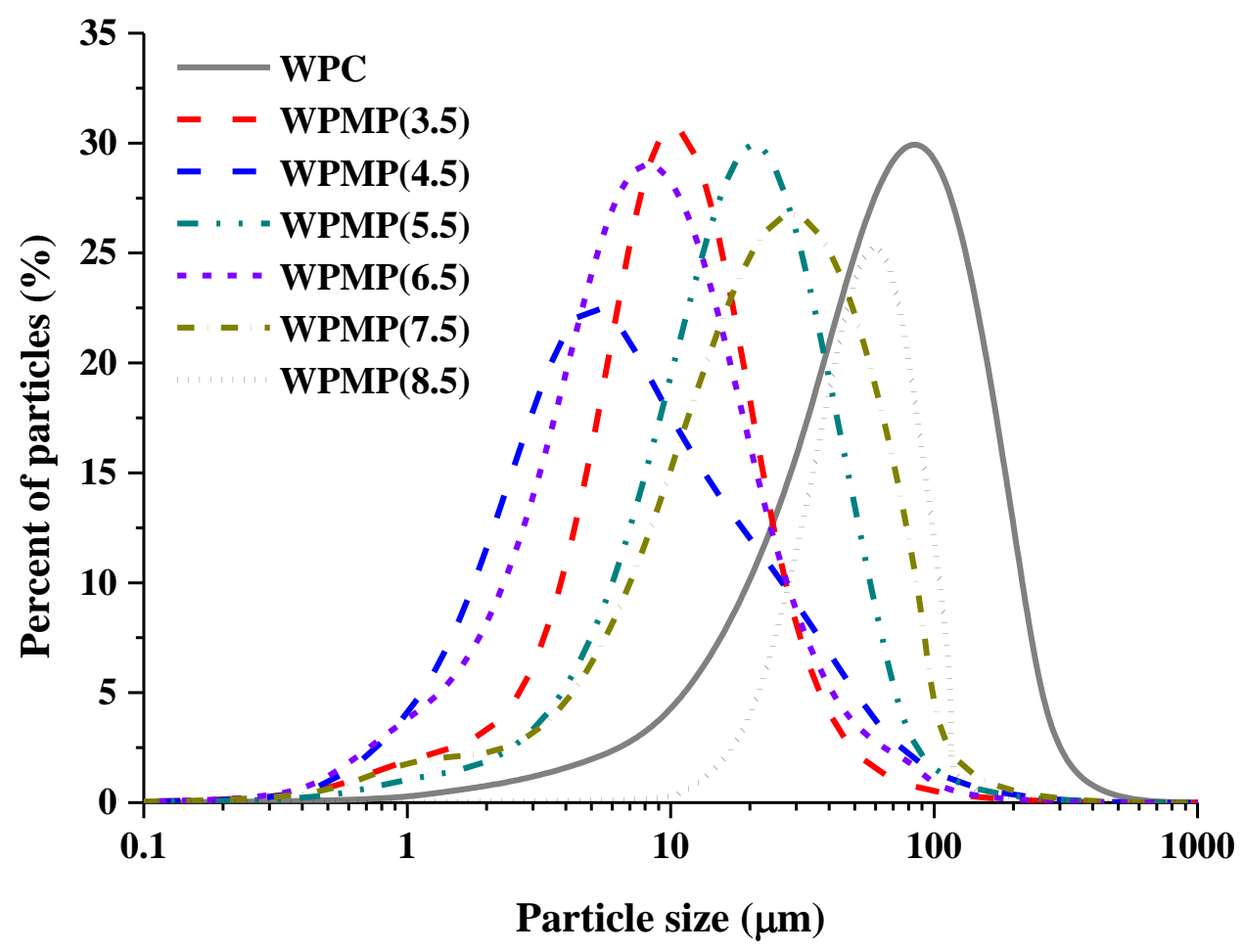

Figure 1. Particle size distributions of WPC and WPMPs.

Table 1. Particle size distribution of WPC and WPMPs.

\begin{tabular}{cccccc}
\hline Samples & $D_{50}(\mu \mathrm{m})$ & $D[2,1]$ & $D[3,2]$ & $D[4,3]$ & SSA $^{*}\left(\mathbf{m}^{2} / \mathbf{g}\right)$ \\
\hline WPC & $45.86 \pm 1.22^{\mathrm{a}}$ & $4.19 \pm 0.02^{\mathrm{a}}$ & $23.83 \pm 0.25^{\mathrm{a}}$ & $50.90 \pm 2.18^{\mathrm{a}}$ & $0.08 \pm 0.01^{\mathrm{a}}$ \\
WPMP(3.5) & $7.54 \pm 0.11^{\mathrm{b}}$ & $1.80 \pm 0.05^{\mathrm{b}, \mathrm{c}}$ & $4.83 \pm 0.06^{\mathrm{b}}$ & $8.39 \pm 0.31^{\mathrm{b}}$ & $0.40 \pm 0.01^{\mathrm{b}}$ \\
WPMP(4.5) & $4.91 \pm 0.21^{\mathrm{c}}$ & $1.52 \pm 0.12^{\mathrm{b}, \mathrm{d}}$ & $3.36 \pm 0.03^{\mathrm{c}}$ & $8.32 \pm 0.76^{\mathrm{b}}$ & $0.58 \pm 0.01^{\mathrm{c}}$ \\
WPMP(5.5) & $13.96 \pm 0.10^{\mathrm{d}}$ & $2.12 \pm 0.05^{\mathrm{c}}$ & $7.91 \pm 0.11^{\mathrm{d}}$ & $15.91 \pm 0.16^{\mathrm{c}}$ & $0.24 \pm 0.01^{\mathrm{d}}$ \\
WPMP(6.5) & $6.19 \pm 0.42^{\mathrm{e}}$ & $1.42 \pm 0.08^{\mathrm{d}}$ & $3.71 \pm 0.15^{\mathrm{c}}$ & $8.78 \pm 0.38^{\mathrm{b}}$ & $0.52 \pm 0.02^{\mathrm{e}}$ \\
WPMP(7.5) & $17.74 \pm 0.13^{\mathrm{f}}$ & $1.51 \pm 0.01^{\mathrm{b}, \mathrm{d}}$ & $7.75 \pm 0.06^{\mathrm{d}}$ & $21.99 \pm 0.22^{\mathrm{e}}$ & $0.25 \pm 0.01^{\mathrm{d}}$ \\
WPMP(8.5) & $46.68 \pm 0.56^{\mathrm{a}}$ & $31.05 \pm 0.31^{\mathrm{e}}$ & $39.84 \pm 0.43^{\mathrm{e}}$ & $48.91 \pm 0.50^{\mathrm{a}}$ & $0.05 \pm 0.01^{\mathrm{f}}$ \\
\hline
\end{tabular}

The values that do not bear the same letter in the same column are significantly different $(p<0.05) . D[4,3], D[3,2]$ and $D[2,1]$ represent volume mean diameter, Sauter mean diameter and linear mean diameter, respectively, * Specific surface area.

The SSA of WPMP(4.5), WPMP(5.5), WPMP(6.5), and WPMP(7.5) steeply increased to $0.40 \mathrm{~m}^{2} / \mathrm{g}, 0.58 \mathrm{~m}^{2} / \mathrm{g}, 0.24 \mathrm{~m}^{2} / \mathrm{g}, 0.52 \mathrm{~m}^{2} / \mathrm{g}, 0.25 \mathrm{~m}^{2} / \mathrm{g}$, which respectively were five times, seven times, three times, six times and three times the SSA of WPC. Higher SSA may lead to differences in stability of the $\mathrm{O} / \mathrm{W}$ emulsions stabilized by the proteins. $D_{50}, D[4,3]$ and SSA of WPMP(8.5) shows no significant difference with these of WPC. However, D[2,1] 
and $D[3,2]$ significantly increased to $31.05 \mu \mathrm{m}$ and $39.84 \mu \mathrm{m}$, which were bigger than these of WPC $(4.19 \mu \mathrm{m}$ and $23.83 \mu \mathrm{m})$. It indicates that the shape of WPMP(8.5) is no longer a spheroid. The results are consistent with our previous observations [20]. In addition to particle size, the shape of protein micro-gel particles is also an important parameter for its adsorption on the oil-water interface, thus affecting the stability of the emulsions [21].

\subsection{Micro-Rheology Measurements of WPMP Dispersions and WPMP-XG Complexes \\ 3.2.1. EI and MVI of Samples}

The viscoelasticity of the emulsifiers (WPMP dispersions and WPMP-XG complexes) is represented by EI and MVI values. Ceniti et al. [22] indicated that the EI corresponds to the inverse of the distance to be covered by particles before interacting with the network, and the MVI corresponds to the inverse of the speed of the particles over long distances. EI values measure elastic features of the emulsifiers, and are linked to end-use properties such as mesh size and hardness of the network. MVI values quantify the microscopic viscosity of the emulsifiers at rest, and can be proportional to the macroscopic viscosity.

As can be seen from Figure 2(a1,b1), the EI and MVI values of WPMP dispersions were significantly higher than those of WPC dispersions. The results indicate that the structure and rheological properties of WPC changed during the preparation of WPMPs at different $\mathrm{pH}$ levels. In the $\mathrm{pH}$ range of 4.5-8.5, with the increase of $\mathrm{pH}, \mathrm{EI}$ and MVI values of WPMPs increased gradually. Protein solutions with high protein concentrations show two behavioral stages during heating, namely molecular unfolding and aggregation [23]. In the first stage, that is, the protein molecular unfolding stage, the protein molecules overcome the intra-molecular force and unfold under the action of solvent (water molecules) and heat treatment. At the same time, the embedded free sulfhydryl and hydrophobic groups are exposed. In the second stage, the unfolded protein molecules are cross-linked with each other to form soluble/insoluble aggregates through hydrogen bonding, hydrophobic interactions and S-S crosslinking. Different $\mathrm{pH}$ values of dispersions significantly affect the charges of protein molecules. Thus, in the first stage, the extent of protein unfolding, and the distribution of amino acid side chains were significantly different. Thus, the network strength and particle size of the protein aggregates formed in the second stage vary significantly with the $\mathrm{pH}$ values of the dispersions. Subsequently, the controlled high-speed shearing treatment destroys the heat-set protein gel and forms protein microgel particles [5]. When the $\mathrm{pH}$ approaches the isoelectric point ( $\sim \mathrm{pH} 4.5)$, the protein molecules have less charge and the intermolecular electrostatic repulsion is weaker than other $\mathrm{pH}$ values. Thus, it is easy to form random micro-aggregates through non-covalent protein-protein interactions [24] which can be easily destroyed into small protein micro-gel particles. The weak interaction between protein miacro-gel particles led that the EI and MVI values of WPMP(3.5), WPMP(4.5) and WPMP(5.5) significantly decreased as the $\mathrm{pH}$ approached the $\mathrm{pI}$. As the $\mathrm{pH}$ value increases from $\mathrm{pH} 5.5$ to $\mathrm{pH} 8.5$, the viscoelasticity of protein miacro-gel particles significantly increased. The formation of compact protein aggregates at $\mathrm{pH}$ 6.5-8.5 could be a major contributor to the high EI and MVI values seen in WPMP(6.5), WPMP(7.5) and WPMP(8.5). 

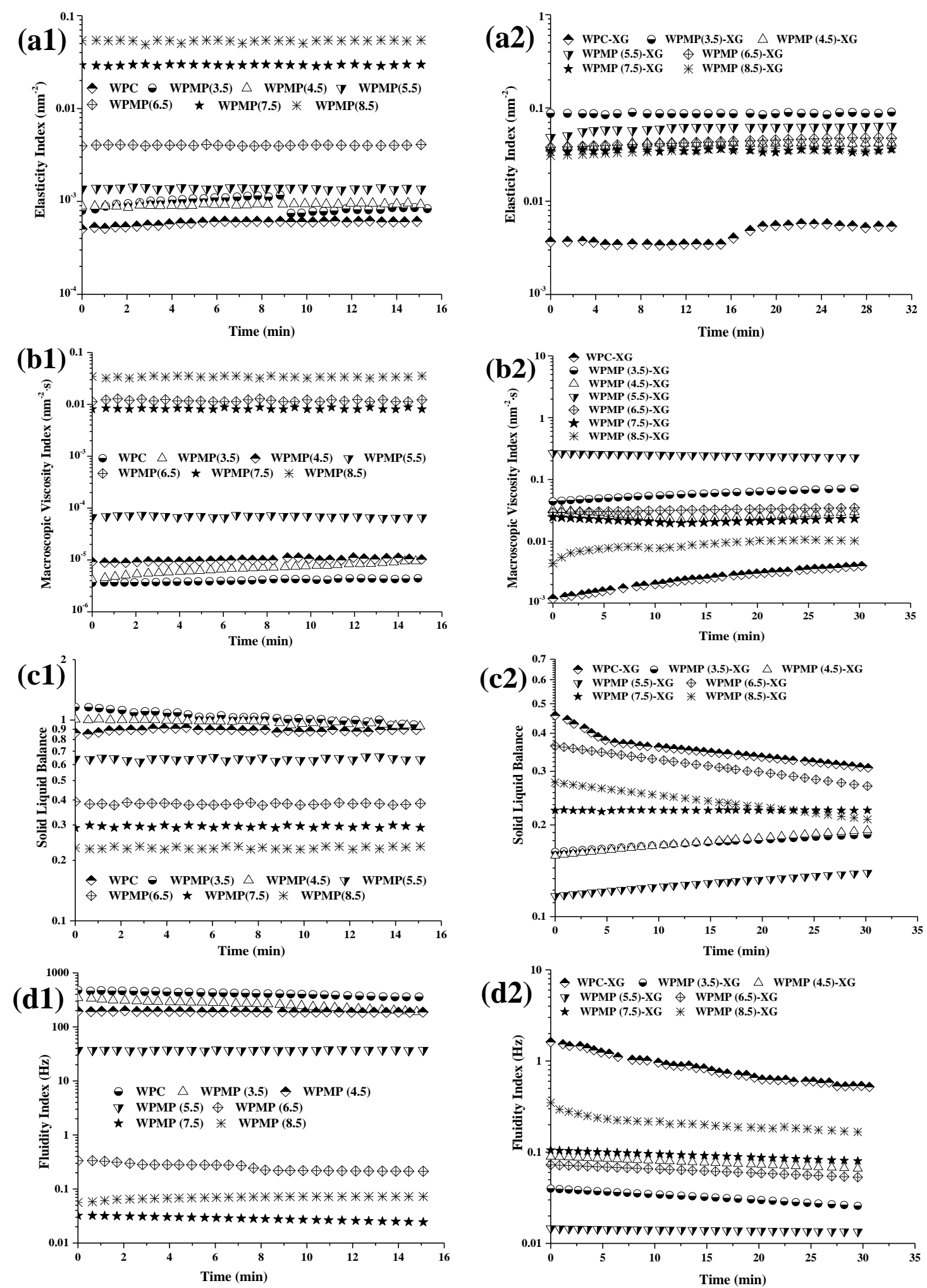

Figure 2. Micro-rheological properties of the proteins (1) and protein-XG complexes (2). (a1,a2): Elasticity index; (b1,b2): Macroscopic viscosity index; (c1,c2): Solid liquid balance; (d1,d2): Fluidity index.

Figure 2(a2,b2) show that the EI and MVI values significantly increased after the addition of XG. WPC-XG showed the lowest EI and MVI values. In addition, WPMP(5.5)-XG, and WPMP(3.5)-XG exhibited higher EI and MVI values than WPMP(4.5)-XG, WPMP(7.5)$X G, W P M P(p H$ 6.5)-XG, and WPMP(8.5)-XG. Thus, it can be concluded that XG formed 
stronger networks with WPMP(5.5) and WPMP(pH 3.5). The $\mathrm{pH}$ values of WPMP dispersions were all $\mathrm{pH} 6.5$, which is higher than the isoelectric point of the whey proteins ( $\alpha$-lactalbumin, $\mathrm{pH} 4.3$; $\beta$-lactoglobulin, $\mathrm{pH} 4.7$; and bovine serum albumin, $\mathrm{pH}$ 5.2). At this time, whey proteins and $X G$ are negatively charged, so the intermolecular repulsion is dominant. According to Bryant \& Mcclements [25], phase separation which is driven by thermodynamic incompatibility occurred between the proteins and polysaccharides in the protein-XG complexes in the neutral $\mathrm{pH}$ range. This is consistent with the research of Laneuville et al. [26] who found that low WP: XG ratios (5:1-10:1) produced principally small incompatibility complexes at the $\mathrm{pH}$ value higher than $\mathrm{pI}$.

It is noteworthy that the viscoelasticity of WPMPs-XG complexes is significantly different. According to our previous research results [27], the unfolding of the native conformation of WPC exposed the hydrophobic amino acids and caused the concomitant burial of some hydrophilic amino acid side chains during the combined treatment of heat treatment and controlled high-speed shear treatment. Changes in the distributions of hydrophobic/hydrophilic amino acid side chains decreased the surface charge density of WPMPs. In WPMPS-XG complexes, the different surface charge density of WPMPs affected the degree of intermolecular repulsion between the WPMPs and XG, which eventually leads to the viscoelasticity difference of the complexes.

\subsubsection{SLB and FI of Samples}

The SLB is directly proportional to the viscoelastic properties of the product and is indicative of the evolution of the ratio between the solid-like and liquid-like behaviour of the product as a function of time. The FI is obtained from the inverse of the characteristic decorrelation time which corresponds to the time needed to reach a relevant speckle pattern decorrelation. Thus, the SLB and FI can be used to compare the rheological behaviours of several samples [5]. SLB $=0$ means that the sample is purely elastic/solid-like, $0<\mathrm{SLB}<0.5$ means that the solid behaviour is dominant (gel behaviour), SLB $=0.5$ means that the liquid and solid behaviours are equal, and $0.5<\mathrm{SLB}<1$ means that the liquid behaviour is dominant [28]. A low FI $\left(\sim 10^{-2} \mathrm{~Hz}\right)$ means that the product is mainly solid-like, and a high FI $(\sim 10 \mathrm{~Hz})$ means that product is mainly fluid-like.

As seen in Figure 2(c1,d1), the SLB and FI values of WPC, WPMP(3.5), WPMP(4.5) and WPMP(5.5) were greater than 0.5 and 10, respectively, indicating that the liquid behaviour dominates in each of these samples. WPC was heated and controlled by high-speed shearing to be used as building blocks to form various types of colloidal particles. The applied treatment reduces the proteins to very small spheroidal particles with a diameter of 4.91-13.96 $\mu \mathrm{m}$. under acidic conditions ( $\mathrm{pH} 3.5-5.5)$. The relative sliding between WPMP particles is the main reason for their good fluidity. The SLB and FI values of WPMP(6.5), WPMP(7.5) and WPMP(8.5) were less than 0.5 and 1, respectively, indicating that the solid behaviour is dominant. The resulting gels formed by heat treatment at $\mathrm{pH}$ above $\mathrm{pH} 6.5$ are more translucent, clastic and rubbery, which were hard to break down or can restore structure quickly [29]. Therefore, the fluidity of the WPMPs was poor.

Figure 2(c2,d2) show that the SLB and FI values of all the protein-XG complexes were less than 0.5 and 10, respectively, indicating that the proteins and XG formed complexes are dominated by gel behaviour. According to our previous studies, XG formed network structures in the complexes, and the WPMPs were evenly dispersed among them [30]. The network blocked the relative sliding of WPMP particles, resulting in the decreasing SLB and increasing FI. The difference of SLB and FI depends on the structural uniformity of the protein-XG incompatibility complexes and the accumulation of WPMPs. The difference of surface charge density of WPMPs caused by the distributions of hydrophobic/hydrophilic amino acid side chains during the combined treatment of heat treatment and controlled high-speed shear treatment is the most fundamental reason.

Based upon the results, the authors made a hypothetic schematic representation of the interaction and distribution of WPMPs and XG which were shown in Figure 3. In the protein-XG complexes, WPMP particles were aggregated and distributed among the 
stable three-dimensional network formed by XG molecules. The degree of WPMP particles aggregation from high to low was WPMP(8.5), WPMP(7.5), WPMPMP(6.5), WPMPMP(4.5), WPMPMP(3.5), and WPMPMP(5.5).

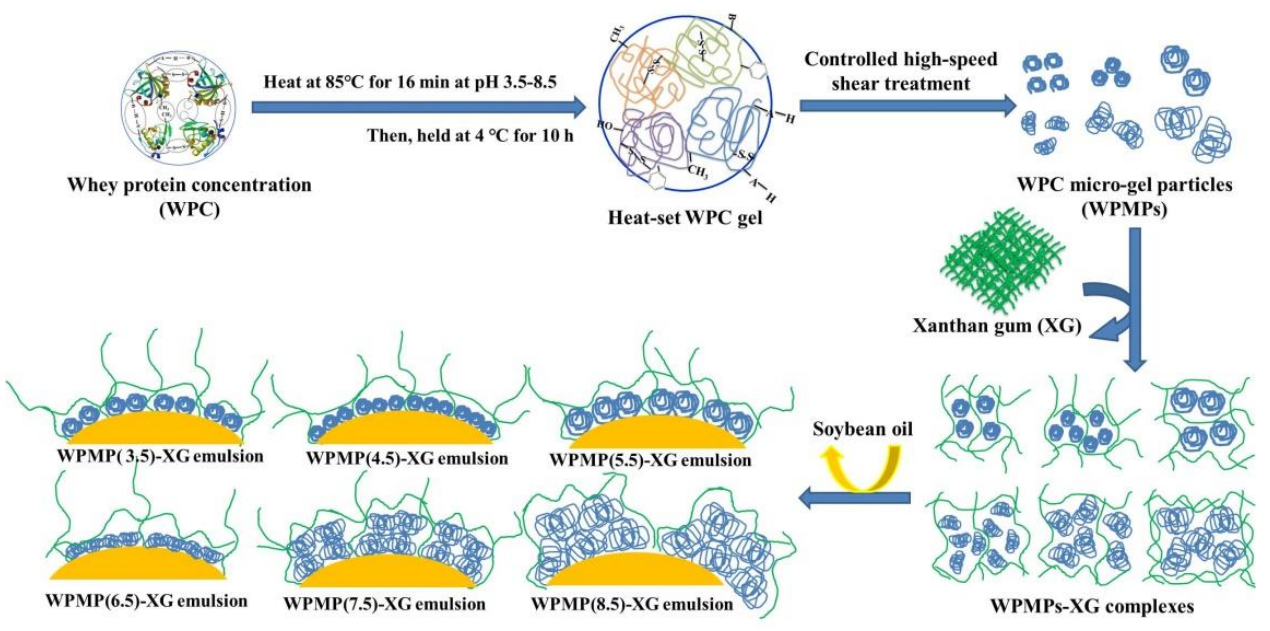

Figure 3. Hypothetic schematic representation of WPMPs, WPMP-XG complexes and interfacial structure of emulsions.

\subsection{Analysis of Stability and Mean Droplet Size}

Figure 4 shows the TSI values of the emulsions stabilized by WPMP dispersions and WPMP-XG complexes during $24 \mathrm{~h}$ of storage at $25^{\circ} \mathrm{C}$. Smaller TSI values indicate higher stability. The emulsion stabilized by WPC was the worst among all the studied emulsion systems, which was evidenced by the remarkable increase in its TSI (up to 17.56). It can be seen from Figure 5(a1,b1) that with the prolongation of storage time in $24 \mathrm{~h}$, the mean droplet size increased significantly at the top (from $7.5 \mu \mathrm{m}$ to $9.0 \mu \mathrm{m}$ ) and in the middle parts (from $9.0 \mu \mathrm{m}$ to $26.2 \mu \mathrm{m}$ ) of the WPC emulsion. This indicates coalescence behavior of oil droplets in the emulsion which is one of the reasons for a significant increase in TSI values. According to Evans, Ratcliffe, \& Williams [31], the result was partly due to that the concentration of dissolved WPs surrounding the smaller droplets was higher than that of the larger droplets, resulting in a concentration gradient. Over time, the gradient made the dissolved molecules move from the smaller droplets to the larger droplets, resulting in the overall increase of droplet size. The TSI values of the WPMPs-stabilized emulsions were significantly smaller than that of the WPC-stabilized emulsion, indicating that the stability of the emulsion is enhanced. After $24 \mathrm{~h}$ of storage, the TSI values from high to low were WPMP(4.5) emulsion, WPMP(3.5) emulsion, WPMP(6.5) emulsion, WPMP(7.5) emulsion, WPMP(8.5) emulsion, and WPMP(5.5) emulsion (Figure 4a). Except for WPMP(4.5) emulsion and WPMP(3.5) emulsion, the TSI curves of other WPMPsstabilized emulsions showed a slow rising trend and reached the highest value at $20 \mathrm{~h}$ of storage time. According to Figure 5(a1,b1), the mean droplet size at the top and in the middle of all WPMPs-stabilized emulsions did not change, suggesting that flocculation between droplets increased the TSI during the $24 \mathrm{~h}$ storage period. The absence of corresponding mean droplet size values at the bottom of all the protein-stabilized emulsions was due to the occurrence of gravitational separation. The results indicate that WPMPs improved the physical stabilize of WPC-stabilized O/W emulsions with high stability against coalescence. 

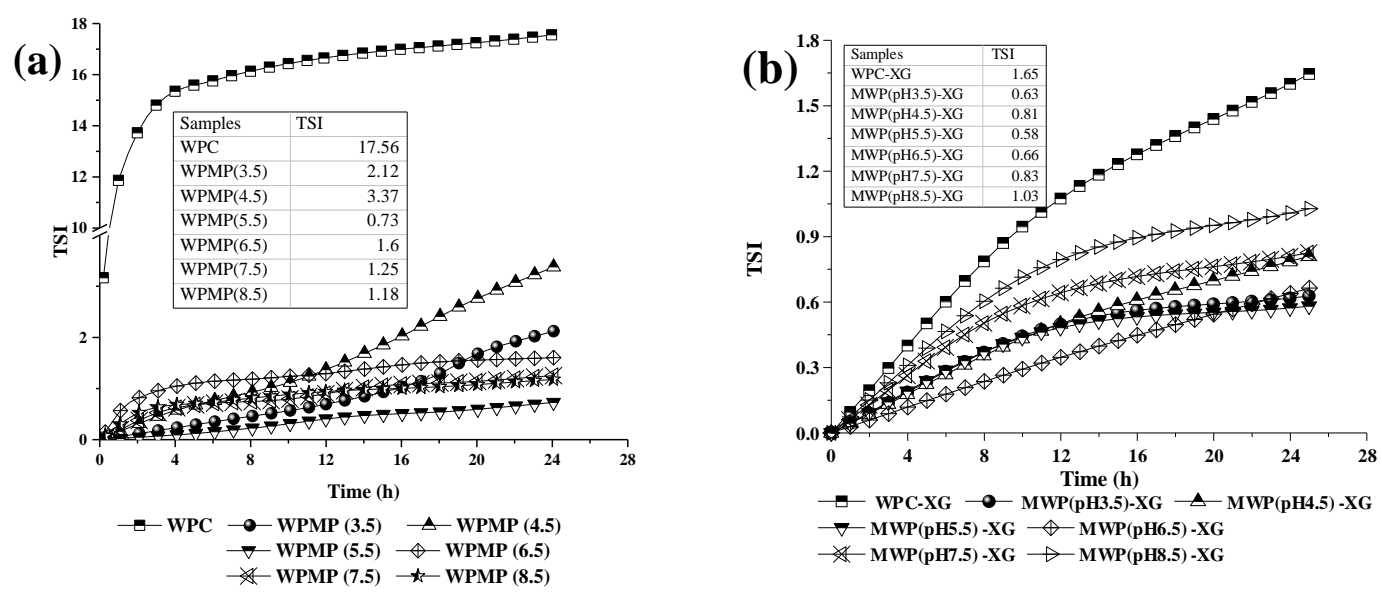

Figure 4. Turbiscan stability index (TSI) of the emulsions stabilized by the proteins (a) and protein-XG complexes (b).
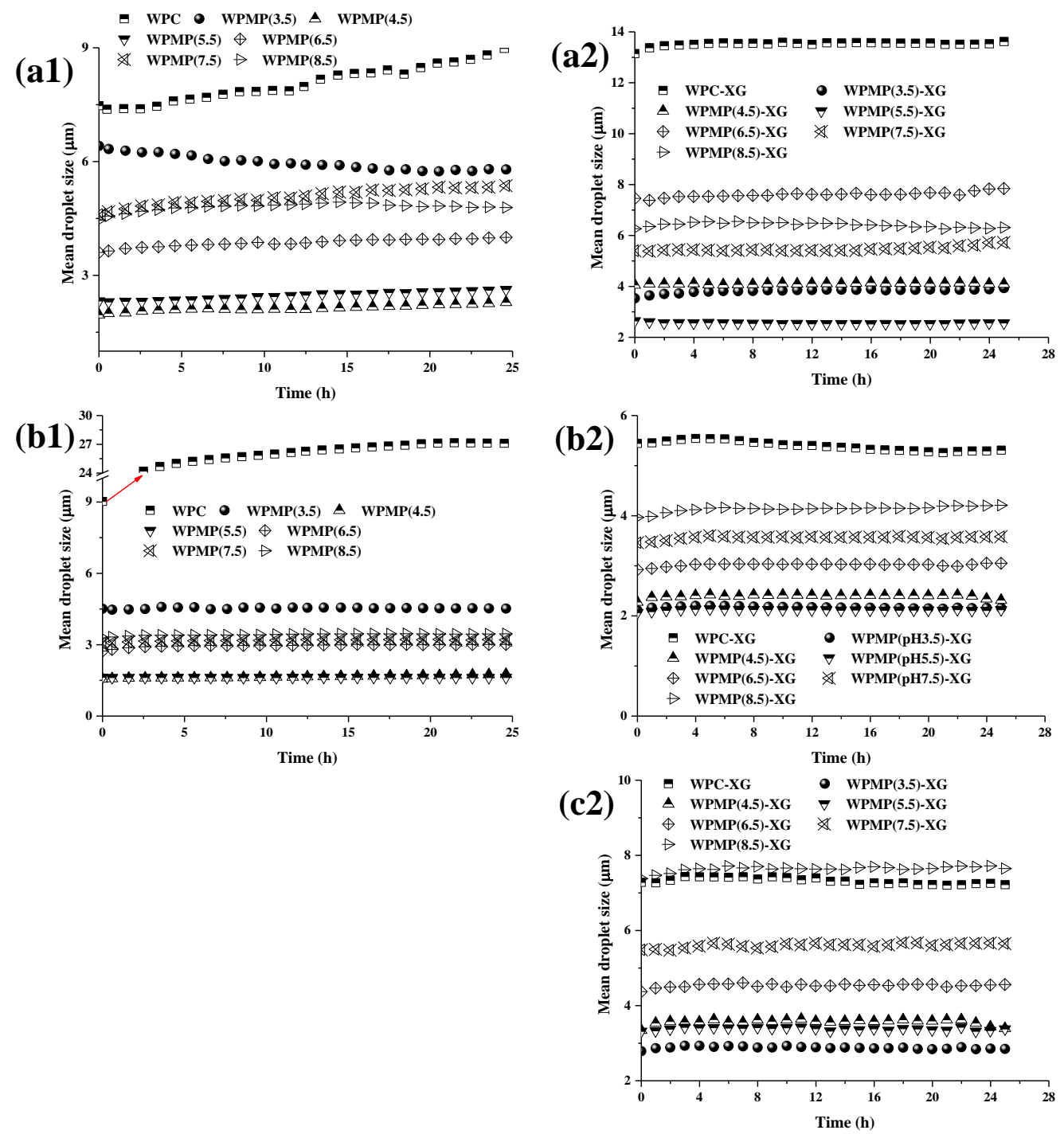

Figure 5. Mean droplet size of the emulsions stabilized by the proteins (1) and protein-XG complexes (2) during storage. $(\mathbf{a 1}, \mathbf{a} 2)$ Mean droplet sizes on the top of the emulsions; $(\mathbf{b 1}, \mathbf{b 2})$ Mean droplet sizes in the middle of emulsions; (c2) Mean droplet sizes on the bottom of the emulsions. No corresponding values for mean droplet size measurements on the bottom of the protein-stabilized emulsions. 
The TSI values of protein-XG complexes-stabilized emulsions were significantly lower than that of protein-stabilized emulsions, indicating that the stability of the emulsions was enhanced by the addition of XG (Figure 4b). According to Figure $4 a, b$, the TSI values of the WPMP(3.5)-XG emulsion, WPMP(4.5)-XG emulsion, WPMP(5.5)-XG emulsion, WPMP(6.5)$X G$ emulsion and WPMP(7.5)-XG emulsion were significantly lower (0.50-0.85) than that of the protein stabilized emulsions (0.75-17.56), indicating the addition of XG enhanced on the emulsion stability. Under neutral conditions ( $\mathrm{pH}$ 6.5) in emulsions, the charge incompatibility between WPMPs and XG played a central role in the stability during storage [32]. Therefore, the charge density on the surface of the WPMPs directly affects the charge incompatibility. Natural whey proteins are small globular proteins with defined molecular conformations. In addition, the hydrophilic groups are widely distributed on the surface, while the hydrophobic groups are buried in the interior of the protein. Thus, the strong electrostatic repulsion between the negatively charged WPMPs and XG in the WPCXG complexes-stabilized emulsion leads to the rapid increase of TSI curves (Figure 4b). In addition, after the combined treatment of heat treatment and controlled high-speed shear treatment at different $\mathrm{pH}$, the hydrophobic interaction of the WPMPs would enhance to varying degrees, while the electrostatic interaction with the XG would be weakened. Thus, the stability of WPMPs-XG complexes-stabilized emulsions would be significantly higher than that of WPC-XG complexes-stabilized emulsions.

Figure 5(a2-c2) show that the mean droplet size of protein-XG complexes-stabilized emulsions did not change significantly during short-term storage. This indicates that oil droplet flocculation is the main reason for the slow rise of TSI values of protein-XG complexes-stabilized emulsions. From the Stokes formula, it can be found that the settling velocity of oil droplets is proportional to the square of their diameter [33]. Therefore, the constant droplet size is the key factor to prevent coalescence of the oil droplets and delay phase separation. According to the micro-rheological properties, stability, and mean droplet size, it can be speculated that XG can prevent the instability of emulsions by shielding the active charged groups of whey proteins and reducing the collision rate among molecules by increasing the viscosity of aqueous phase [34,35]. Therefore, the results showed that $X G$ addition can inhibit droplet coalescence and gravitational separation to improve the physical stability of WPC-stabilized $\mathrm{O} / \mathrm{W}$ emulsions.

\subsection{Measuring the PVs of the Emulsions}

Lipid oxidation is a process which is influenced by many factors, such as the lipid droplet size, emulsifier type and concentration [36]. The oxidative stability of the emulsions entails measurement of the levels of primary oxidation product generated during 17 days of storage. Hydroperoxides are the primary oxidation product and can be quantified via the PVs. Figure 6a shows the PVs of soybean oil and protein (WPC and WPMPs)-stabilized emulsions throughout a 17-day period. As the storage period progressed, the PVs of all emulsions significantly increased, indicating that all emulsions were oxidized. The relationship between the PVs (y) and storage time (x) was successfully fitted by the power-law model, $y=a(1+x)^{b}$ (Table 2). The power law indexes $b$ of WPC emulsion, WPMP(3.5) emulsion, WPMP(4.5) emulsion, WPMP(5.5) emulsion and WPMP(6.5) emulsion are significantly greater than that of soybean oil (Table 2), indicating not only a greater rate but also a higher extent of oxidation. However, the $b$ values of WPMP(7.5) emulsion and WPMP(8.5) emulsion were significantly lower than those of soybean oil, indicating good oxidation stability. The difference can be attributed to the dispersion of soybean oil in $\mathrm{O} / \mathrm{W}$ emulsion into droplets in aqueous phase containing oxidants and oxygen [37]. Thus, the increased surface contact area caused high oxidative stress and promoted lipid oxidation in the O/W emulsions. Emulsions stabilized by WPMPs had significantly lower PVs than the WPC-stabilized emulsion (Figure 6a). The difference can be attributed to the aggregation and coalescence of lipid droplets in WPC-stabilized emulsion, which brought the lipid phases closer and facilitated the transfer of lipophilic pro-oxidants among the droplets. Notably, the PVs and $b$ values of the WPMP(7.5) emulsion and WPMP(8.5) emulsion were 
significantly lower than those of the soybean oil after 17 days of storage, indicating that lipid oxidation in O/W emulsions can be inhibited by WPMP(7.5) and WPMP(8.5). The lipid droplet size is an important factor affecting the oxidative stability of $\mathrm{O} / \mathrm{W}$ emulsions. With the increase of lipid droplet size, the PVs of emulsion significantly decrease and the oxidative stability of emulsions increases. However, PV results of WPMPs-stabilized emulsions were not exactly in the same order as that of the mean droplet size, indicating that the initial structure of the proteins was a more important factor affecting the oxidative stability of the $\mathrm{O} / \mathrm{W}$ emulsions.
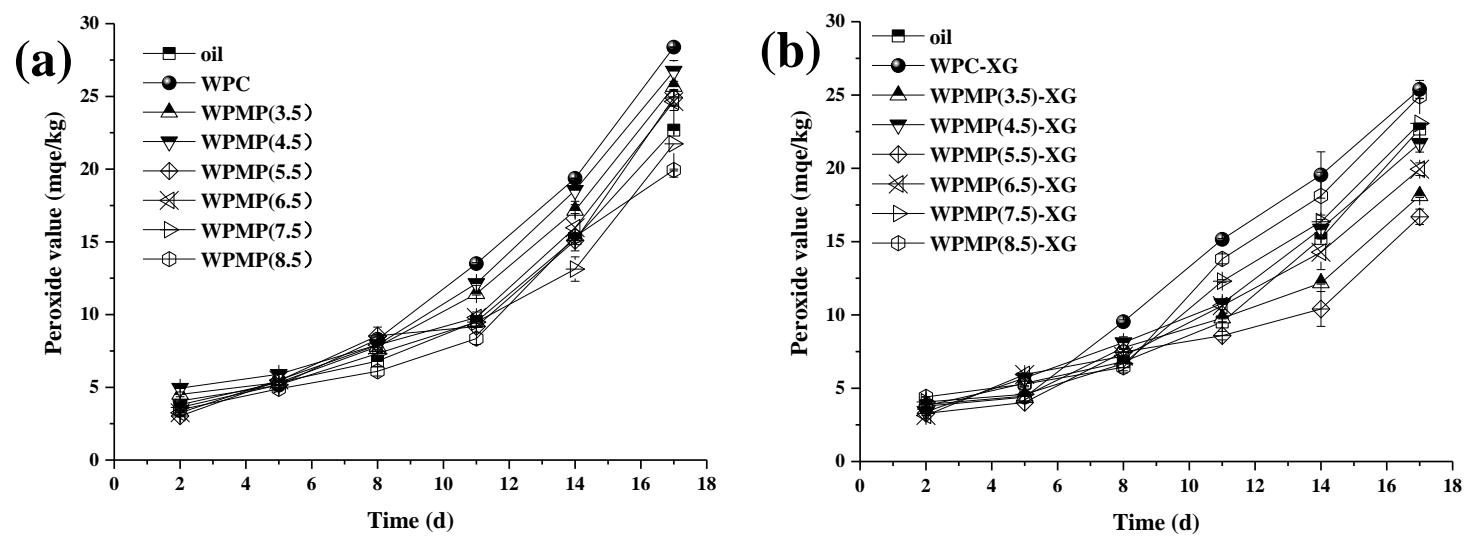

Figure 6. Peroxide values (PV) of the emulsions stabilized by the proteins (a) and protein-XG complexes (b) as a function of storage time.

Table 2. Relevant parameters of oxidative kinetic model.

\begin{tabular}{cccc}
\hline \multirow{2}{*}{ Samples } & \multicolumn{3}{c}{$\mathbf{y = \mathbf { a } ( \mathbf { 1 } + \mathbf { x } \mathbf { b } ^ { \mathbf { b } }}$} \\
\cline { 2 - 4 } & $\mathbf{a}$ & $\mathbf{b}$ & $\mathbf{R}^{\mathbf{2}}$ \\
\hline oil & 0.51 & 1.58 & 0.93 \\
WPC & 0.24 & 1.64 & 0.97 \\
WPMP(3.5) & 0.25 & 1.58 & 0.94 \\
WPMP(4.5) & 0.29 & 1.59 & 0.94 \\
WPMP(5.5) & 0.18 & 1.67 & 0.92 \\
WPMP(6.5) & 0.20 & 1.65 & 0.94 \\
WPMP(7.5) & 0.28 & 1.48 & 0.91 \\
WPMP(8.5) & 0.23 & 1.53 & 0.93 \\
WPC-XG & 0.48 & 1.37 & 0.98 \\
WPMP(3.5)-XG & 0.60 & 1.15 & 0.93 \\
WPMP(4.5)-XG & 0.46 & 1.32 & 0.97 \\
WPMP(5.5)-XG & 0.52 & 1.17 & 0.91 \\
WPMP(6.5)-XG & 0.51 & 1.25 & 0.96 \\
WPMP(7.5)-XG & 0.40 & 1.50 & 0.96 \\
WPMP(8.5)-XG & 0.41 & 1.51 & 0.95 \\
\hline
\end{tabular}

Figure $6 \mathrm{~b}$ shows that the PVs of protein-XG complexes-stabilized emulsions decreased sequentially, WPC-XG emulsion, WPMP(8.5)-XG emulsion, WPMP(7.5)-XG emulsion, WPMP(4.5)XG emulsion, WPMP(6.5)-XG emulsion, WPMP(3.5)-XG emulsion, and WPMP(5.5)-XG emulsion. The power-law indexes, $b$, were significantly smaller for WPC-XG emulsion, WPMP(3.5)-XG emulsion, WPMP(4.5)-XG emulsion, WPMP(5.5)-XG emulsion, WPMP(6.5)$X G$ emulsion than for the corresponding protein-stabilized emulsions (Table 2). And $b$ values decreased in the order of WPMP(8.5)-XG emulsion, WPMP(7.5)-XG emulsion, WPC-XG emulsion, WPMP(4.5)-XG emulsion, WPMP(6.5)-XG emulsion, WPMP(5.5)-XG emulsion, and WPMP(3.5)-XG emulsion (Table 2). Compared with Figure $6 a, b$, it can be found that the PVs of emulsions stabilized by protein-XG complexes except WPMP(7.5)-XG and WPMP(8.5)$X G$ were significantly lower than those of protein-stabilized emulsions. This may be due 
to that XG forms a consecutive layer outside the protein interface, which further prevents the water-soluble oxidant and oxygen in the water phase from contacting with the lipid. The results are consistent with other previous studies [38-40] that the addition of XG can inhibit lipid oxidation in $\mathrm{O} / \mathrm{W}$ emulsions. They found that it was attributed to that XG can chelate transition metals such as iron in the aqueous phase at neutral $\mathrm{pH}$. In addition, they can increase the interfacial film thickness and provide a more robust barrier between dispersed phase and continuous phase.

However, PV values of WPMP(8.5)-XG emulsion were significantly greater than those of WPMP(8.5) emulsion (Figure $6 a, b)$. This may be due to that WPMP(8.5) can form a dense protein adsorption layer on the surface of the lipid droplets, thus blocking the contact between water-soluble oxidant and oxygen in the water phase with the lipid phase. However, in WPMP(8.5)-XG emulsion, the protein adsorption layer was blocked by $X G$ molecules into several discontinuous layers, providing contact sites for oxidant and oxygen (Figure 7). These results indicate that the effect of XG on the oxidative stability of $\mathrm{O} / \mathrm{W}$ emulsion is also controlled by the interfacial structure of protein-XG. This finding indicates that the high oxidative stability of emulsion can be achieved by directional design of the interfacial structure of the protein-polysaccharide complexes. The PV results illustrate the potential applications of $\mathrm{MWP}(\mathrm{pH} 7.5), \mathrm{MWP}(\mathrm{pH} 8.5), \mathrm{MWP}(\mathrm{pH} 3.5)-X \mathrm{G}$ and $\mathrm{MWP}(\mathrm{pH}$ 5.5)-XG as emulsifiers for the production of $\mathrm{O} / \mathrm{W}$ emulsions containing lipid phases that are susceptible to oxidation.

\section{Conclusions}

Micro-gel pariticles with mean particle sizes $\left(D_{50}\right)$ of $7.54 \mu \mathrm{m}, 4.91 \mu \mathrm{m}, 13.96 \mu \mathrm{m}$, $6.19 \mu \mathrm{m}, 17.74 \mu \mathrm{m}$, and $46.68 \mu \mathrm{m}$ can be formed by controlled high-speed shear homogenization of heat-set WPC gel at $\mathrm{pH}$ 3.5-8.5. The micro-rheological properties indicated that low WP: XG ratios (7.5:1) principally produced low incompatibility complexes at $\mathrm{pH}$ values higher than $\mathrm{pI}$. TSI curves and mean droplet size curves indicated that the shortterm storage stability of WPC-stabilized emulsion was worse than that of other emulsions due to the occurred coalescence, flocculation, and gravitational separation. The increase of TSI values of WPMPs-stabilized emulsions was caused by flocculation, and gravitational separation. The reason for the rise of TSI curves of protein-XG stabilized emulsions is flocculation. Thus, WPMPs and XG can respectively inhibit droplet coalescence and gravitational separation to improve the physical stability of the emulsions.

PV results of WPMPs-stabilized emulsions were not exactly in the same order as that of the mean droplet size, indicating that the initial structure of the proteins was a more important factor affecting the oxidative stability of the protein-stabilized emulsions. Pretreatment (controlled high-speed shear homogenization of heat-set WPC gel) significantly enhanced the oxidative stability of $\mathrm{O} / \mathrm{W}$ emulsions. The addition of XG does not necessarily enhance the oxidative stability of $\mathrm{O} / \mathrm{W}$ emulsions. Therefore, whether the oxidative stability of $\mathrm{O} / \mathrm{W}$ emulsions of $\mathrm{XG}$ addition is enhanced or weakened depends on the interfacial structure of the protein-XG complexes. Such WPMPs and WPMP-XG complexes exhibited an excellent capacity to prepare gel-like emulsions, and would be useful as functional ingredients to prepare emulsion-based products in the biotechnological, pharmaceutical, and food industries.

Author Contributions: Conceptualization, C.S. and B.L.; methodology, M.Z.; software, C.J.; validation, M.Z. and T.C.; formal analysis, M.Z.; investigation, B.L.; resources, C.S.; data curation, B.L.; writingoriginal draft preparation, M.Z.; writing-review and editing, B.L.; visualization, H.H.; supervision, C.S.; project administration, C.S.; funding acquisition, C.S. and B.L. All authors have read and agreed to the published version of the manuscript.

Funding: This research was supported by Natural Science Foundation of Tianjin City (18JCQNJC84200), Natural Science Foundation of Shandong Province (ZR2020QC219), Natural Science Foundation of Shandong Province (ZR2019BC036) and Incubation Program of Youth Innovation in Shandong Province.

Institutional Review Board Statement: Not applicable. 
Informed Consent Statement: Not applicable.

Data Availability Statement: All the experimental data presented herein are available upon request from the corresponding author.

Conflicts of Interest: The authors declare no conflict of interest.

\section{References}

1. Klinchongkon, K.; Khuwijitjaru, P.; Adachi, S.; Bindereif, B.; Karbstein, H.P.; van der Schaaf, U.S. Emulsifying properties of conjugates formed between whey protein isolate and subcritical-water hydrolyzed pectin. Food Hydrocoll. 2019, 91, 174-181. [CrossRef]

2. Qiu, C.; Zhao, M.; Decker, E.A.; McClements, D.J. Influence of protein type on oxidation and digestibility of fish oil-in-water emulsions: Gliadin, caseinate, and whey protein. Food Chem. 2015, 175 (Suppl. C), 249-257. [CrossRef]

3. Obando, M.; Papastergiadis, A.; Li, S.; De Meulenaer, B. Impact of Lipid and Protein Co-oxidation on Digestibility of Dairy Proteins in Oil-in-Water (O/W) Emulsions. J. Agric. Food Chem. 2015, 63, 9820-9830. [CrossRef] [PubMed]

4. Qayum, A.; Li, M.; Shi, R.; Bilawal, A.; Gantumur, M.-A.; Hussain, M.; Ishfaq, M.; Waqas Ali Shah, S.; Jiang, Z.; Hou, J. Laccase cross-linking of sonicated $\alpha$-Lactalbumin improves physical and oxidative stability of CLA oil in water emulsion. Ultrason. Sonochem. 2021, 71, 105365. [CrossRef] [PubMed]

5. Sun, C.; Wu, T.; Liu, R.; Liang, B.; Tian, Z.; Zhang, E.; Zhang, M. Effects of superfine grinding and microparticulation on the surface hydrophobicity of whey protein concentrate and its relation toemulsions stability. Food Hydrocoll. 2015, 51, 512-518. [CrossRef]

6. Sun, C.; Gunasekaran, S. Rheology and Oxidative Stability of Whey Protein Isolate-Stabilized Menhaden Oil-in-Water Emulsions as a Function of Heat Treatment. J. Food Sci. 2010, 75, C1-C8. [CrossRef]

7. Noello, C.; Carvalho, A.G.S.; Silva, V.M.; Hubinger, M.D. Spray dried microparticles of chia oil using emulsion stabilized by whey protein concentrate and pectin by electrostatic deposition. Food Res. Int. 2016, 89, 549-557. [CrossRef]

8. Xu, X.; Liu, W.; Luo, L.; Liu, C.; McClements, D.J. Influence of anionic polysaccharides on the physical and oxidative stability of hydrolyzed rice glutelin emulsions: Impact of polysaccharide type and pH. Food Hydrocoll. 2017, 72 (Suppl. C), 185-194. [CrossRef]

9. Griffin, K.; Khouryieh, H. Influence of electrostatic interactions on the formation and stability of multilayer fish oil-in-water emulsions stabilized by whey protein-xanthan-locust bean complexes. J. Food Eng. 2020, 277, 109893. [CrossRef]

10. Zhang, M.; Sun, C.; Li, Q. Interaction between the Polysaccharides and Proteins in Semisolid Food Systems. In Encyclopedia of Food Chemistry; Melton, L., Shahidi, F., Varelis, P., Eds.; Academic Press: Oxford, UK, 2019; pp. 439-445.

11. Le, X.T.; Rioux, L.E.; Turgeon, S.L. Formation and functional properties of protein-polysaccharide electrostatic hydrogels in comparison to protein or polysaccharide hydrogels. Adv. Colloid Interface Sci. 2016, 239, 127-135. [CrossRef]

12. Tisserand, C.; Fleury, M.; Brunel, L.; Bru, P.; Meunier, G. Passive Microrheology for Measurement of the Concentrated Dispersions Stability. In UK Colloids 2011: An International Colloid and Surface Science Symposium; Starov, V., Griffiths, P., Eds.; Springer: Berlin/Heidelberg, Germany, 2012; pp. 101-105.

13. Sarwar, A.; Aziz, T.; Al-Dalali, S.; Zhang, J.; Din Ju Chen, C.; Cao, Y.; Fatima, H.; Yang, Z. Characterization of synbiotic ice cream made with probiotic yeast Saccharomyces boulardii CNCM I-745 in combination with inulin. LWT Food Sci. Technol. 2021, 141, 110910. [CrossRef]

14. Raikos, V. Encapsulation of vitamin E in edible orange oil-in-water emulsion beverages: Influence of heating temperature on physicochemical stability during chilled storage. Food Hydrocoll. 2017, 72 (Suppl. C), 155-162. [CrossRef]

15. Su, Y.-R.; Tsai, Y.-C.; Hsu, C.-H.; Chao, A.-C.; Lin, C.-W.; Tsai, M.-L.; Mi, F.-L. Effect of Grape Seed Proanthocyanidin-Gelatin Colloidal Complexes on Stability and in Vitro Digestion of Fish Oil Emulsions. J. Agric. Food Chem. 2015, 63, 10200-10208. [CrossRef] [PubMed]

16. Chinese Standard GB/T5009.37-2003. Method for Analysis of Hygienic Standard of Edible Oils; Standards Press of China: Beijing, China, 2003.

17. Chen, N.; Lin, L.; Sun, W.; Zhao, M. Stable and pH-Sensitive Protein Nanogels Made by Self-Assembly of Heat Denatured Soy Protein. J. Agric. Food Chem. 2014, 62, 9553-9561. [CrossRef]

18. Liu, K.; Kong, X.L.; Li, Q.M.; Zhang, H.L.; Zha, X.Q.; Luo, J.P. Stability and bioavailability of vitamin D3 encapsulated in composite gels of whey protein isolate and lotus root amylopectin. Carbohydr. Polym. 2020, 227, 9. [CrossRef]

19. He, Z.; Ma, T.; Zhang, W.; Su, E.; Cao, F.; Huang, M.; Wang, Y. Heat-induced gel formation by whey protein isolate-Lycium barbarum polysaccharides at varying pHs. Food Hydrocoll. 2021, 115, 106607. [CrossRef]

20. Sun, C.; Liu, R.; Sheng, H.; Wang, R.; Zhang, Z.; Zhao, J.; Zhang, M. Effect of microparticulation and xanthan gum on the stability and lipid digestion of oil-in-water emulsions stabilized by whey protein. Food Funct. 2018, 9, 4683-4694. [CrossRef]

21. Hazt, B.; Bassani, H.P.; Elias-Machado, J.P.; Aldinucci Buzzo, J.L.; Silveira, J.L.M.; de Freitas, R.A. Effect of pH and protein particle shape on the stability of amylopectin-xyloglucan water-in-water emulsions. Food Hydrocoll. 2020, 104, 105769. [CrossRef]

22. Ceniti, C.; Froiio, F.; Britti, D.; Paolino, D.; Costanz, N. Rheological characteristics of bovine colostrum and their correlation with immunoglobulin G. Int. J. Dairy Technol. 2019, 72, 345-349. [CrossRef] 
23. Chihi, M.-L.; Mession, J.-L.; Sok, N.; Saurel, R. Heat-Induced Soluble Protein Aggregates from Mixed Pea Globulins and $\beta$-Lactoglobulin. J. Agric. Food Chem. 2016, 64, 2780-2791. [CrossRef] [PubMed]

24. Choi, S.-M.; Ma, C.-Y. Conformational study of globulin from common buckwheat (Fagopyrum esculentum Moench) by Fourier transform infrared spectroscopy and differential scanning calorimetry. J. Agric. Food Chem. 2005, 53, 8046-8053. [CrossRef]

25. Bryant, C.M.; Mcclements, D.J. Influence of xanthan gum on physical characteristics of heat-denatured whey protein solutions and gels. Food Hydrocoll. 2000, 14, 383-390. [CrossRef]

26. Laneuville, S.I.; Paquin, P.; Turgeon, S.L. Effect of preparation conditions on the characteristics of whey protein-Xanthan gum complexes. Food Hydrocoll. 2000, 14, 305-314. [CrossRef]

27. Sun, C.C.; Liu, R.; Liang, B.; Wu, T.; Sui, W.J.; Zhang, M. Microparticulated whey protein-pectin complex: A texture-controllable gel for low-fat mayonnaise. Food Res. Int. 2018, 108, 151-160. [CrossRef] [PubMed]

28. Tan, Y.; Wang, J.; Chen, F.; Niu, S.; Yu, J. Effect of protein oxidation on kinetics of droplets stability probed by microrheology in $\mathrm{O} / \mathrm{W}$ and $\mathrm{W} / \mathrm{O}$ emulsions of whey protein concentrate. Food Res. Int. 2016, 85, 259-265. [CrossRef] [PubMed]

29. He, J.-S.; Azuma, N.; Yang, H. Effects of $\mathrm{pH}$ and ionic strength on the rheology and microstructure of a pressure-induced whey protein gel. Int. Dairy J. 2010, 20, 89-95. [CrossRef]

30. Sun, C.; Liu, R.; Wu, T.; Liang, B.; Shi, C.; Cong, X.; Zhang, M. Combined Superfine Grinding and Heat-Shearing Treatment for the Microparticulation of Whey Proteins. Food Bioprocess Technol. 2016, 9, 1-9. [CrossRef]

31. Evans, M.; Ratcliffe, I.; Williams, P.A. Emulsion stabilisation using polysaccharide-protein complexes. Curr. Opin. Colloid Interface Sci. 2013, 18, 272-282. [CrossRef]

32. Du, Q.; Wang, S.; Lyu, F.; Liu, J.; Ding, Y. The interfacial covalent bonding of whey protein hydrolysate and pectin under high temperature sterilization: Effect on emulsion stability. Colloids Surf. B Biointerfaces 2021, 206, 111936. [CrossRef] [PubMed]

33. Liu, J.; Huang, X.; Lu, L.; Li, M.; Xu, J.; Deng, H. Expert analysis of the biological demulsification of a water-in-oil emulsion by two biodemulsifiers. J. Hazard. Mater. 2011, 190, 214-221. [CrossRef]

34. Drakos, A.; Kiosseoglou, V. Stability of Acidic Egg White Protein Emulsions Containing Xanthan Gum. J. Agric. Food Chem. 2006, 54, 10164-10169. [CrossRef] [PubMed]

35. Chen, X.; Li, W.; Zhao, Q.; Selomulya, C.; Zhu, X.; Xiong, H. Physical and oxidative stabilities of o/w emulsions formed with rice dreg protein hydrolysate: Effect of xanthan gum rheology. Food Bioprocess Tech. 2016, 9, 1380-1390. [CrossRef]

36. Noon, J.; Mills, T.B.; Norton, I.T. The use of antioxidant rutin hydrate Pickering particles to combat lipid oxidation in O/W emulsions. J. Food Eng. 2020, 274, 109830. [CrossRef]

37. García-Moreno, P.J.; Guadix, A.; Guadix, E.M.; Jacobsen, C. Physical and oxidative stability of fish oil-in-water emulsions stabilized with fish protein hydrolysates. Food Chem. 2016, 203 (Suppl. C), 124-135. [CrossRef]

38. Shimada, K.; Muta, H.; Nakamura, Y.; Okada, H.; Matsuo, K.; Yoshioka, S.; Nakamura, T. Iron-binding property and antioxidative activity of xanthan on the autoxidation of soybean oil in emulsion. J. Agric. Food Chem. 1994, 42, 1607-1611. [CrossRef]

39. Sun, C.; Gunasekaran, S. Effects of protein concentration and oil-phase volume fraction on the stability and rheology of menhaden oil-in-water emulsions stabilized by whey protein isolate with xanthan gum. Food Hydrocoll. 2009, 23, 165-174. [CrossRef]

40. Sun, C.; Gunasekaran, S.; Richards, M.P. Effect of xanthan gum on physicochemical properties of whey protein isolate stabilized oil-in-water emulsions. Food Hydrocoll. 2007, 21, 555-564. [CrossRef] 